
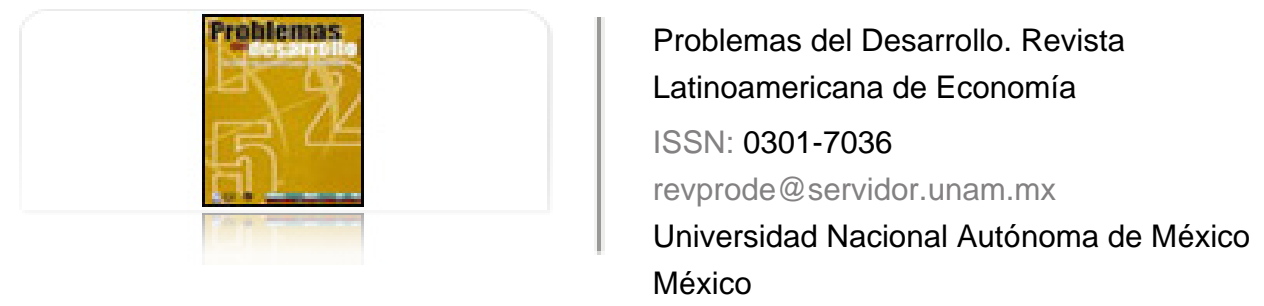

Bekerman, Marta; Cerdeiro, Diego A.

\title{
CRISIS Y PATRÓN DE ESPECIALIZACIÓN COMERCIAL EN ECONOMÍAS EMERGENTES. EL
} CASO DE ARGENTINA

Problemas del Desarrollo. Revista Latinoamericana de Economía, vol. 38, núm. 150, julio-septiembre, 2007, pp. 133-165

Universidad Nacional Autónoma de México

Distrito Federal, México

Disponible en: http://www.redalyc.org/articulo.oa?id=11820083006

Cómo citar el artículo

- Número completo

- Más información del artículo

Página de la revista en redalyc.org

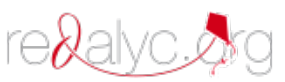

Sistema de Información Científica

Red de Revistas Científicas de América Latina, el Caribe, España y Portugal Proyecto académico sin fines de lucro, desarrollado bajo la iniciativa de acceso abierto 


\title{
CRISIS Y PATRÓN DE ESPECIALIZACIÓN COMERCIAL
}

\section{EN ECONOMÍAS EMERGENTES. EL CASO DE ARGENTINA}

\author{
Marta Bekerman* \\ Diego A. Cerdeiro**
}

Fecha de recepción: 27 de marzo de 2007. Fecha de aceptación: 24 de mayo de 2007.

\section{Resumen}

A partir de las profundas transformaciones en la economia argentina durante los años recientes, se analiza la evolución del patrón de especialización comercial, debido a sus efectos sobre la sustentabilidad de largo plazo del crecimiento económico y la distribución del ingreso. Se demuestra que, a pesar de que se observa recientemente una fuerte expansión de las exportaciones, el patrón de especialización comercial continúa reflejando un perfil concentrado en bienes primarios y manufacturas de bajo nivel tecnológico y contenido de empleo. Es decir, aún no se produjo una transformación estructural en la competitividad de los sectores no asociados a los recursos naturales frente a los que los utilizan de forma abundante. Sin embargo, este fenómeno tiene lugar en un contexto que muestra modificaciones importantes en la distribución de los saldos comerciales con los distintos socios, en donde China comienza a adquirir un papel relevante. El trabajo apunta, asimismo, a observar la relación entre dichas modificaciones y la evolución del patrón de especialización.

Palabras clave: desarrollo económico, patrón de especialización comercial, ventaja comparativa, apertura comercial, integración regional.

* Directora del Centro de Estudios de la Estructura Económica (CENES) de la Facultad de Ciencias Económicas de la Universidad de Buenos Aires (UBA) y Profesora Titular de Desarrollo Económico de dicha Facultad. Además es investigadora principal del Consejo Nacional de Investigaciones Científicas y Técnicas (CONICET). Correo electrónico: bekerman@econ.uba.ar

* Licenciado en Economía y docente de la UBA. Investigador del CENES. Correo electrónico: cerdeiro@econ.uba.ar y diegocerdeiro@yahoo.com.ar

Se agradecen las valiosas sugerencias de tres dictaminadores anónimos. Los errores son responsabilidad exclusiva de los autores. 
Starting from the profound transformations in the Argentine economy in recent years, this paper analyzes the evolution of trade specialization patterns, due to their effects on the long-term sustainability of economic growth and income distribution. This shows that, although a strong expansion in exports has been seen recently, the pattern of trade specialization continues to reflect a concentrated profile of primary goods and manufactures with low-level technology and job content. In other words, there has still been no structural transformation in the competitiveness of sectors unassociated with natural resources, compared with those that make abundant use of them. However, this phenomenon is taking place in a context where important modifications are occurring in the distribution of trade balances with different partners, where China is starting to acquire an important role. At the same time, the study points to the relationship between these modifications and the evolution of the pattern of specialization.

Key words: economic development, pattern of trade specialization, comparative advantage, commercial opening, regional integration.

\section{Résumé}

Au travers des profondes transformations vécues par l'économie argentine au cours des dernières années, cet article analyse l'évolution du modèle de la spécialisation commerciale, au vu de ses effets sur la durabilité à long terme de la croissance économique et la distribution du revenu. On démontrera que, quand bien même une forte expansion des exportations a été observée récemment, ce modèle de la spécialisation commerciale continue à se centrer sur des biens primaires et des manufactures de bas niveau technologique et faible contenu d'emploi. Autrement dit, il n'a toujours pas été effectué une transformation structurale qui accroissent la compétitivité des secteurs non associés à l'exploitation des ressources naturelles face à ceux qui les exploitent intensivement. Pourtant, cet état de fait s'inscrit dans un contexte d'importantes modifications en ce qui concerne la distribution des soldes commerciaux entre les divers associés, où la Chine commence notamment à acquérir un rôle prépondérant. Ce travail vise donc à observer le rapport entre les dites modifications et l'évolution du modèle de spécialisation.

Glossaire: développement économique, modèle de spécialisation commerciale, avantage comparatif, ouverture commerciale, intégration régionale.

Resumo

A partir das profundas transformações na economia argentina durante os anos recentes, se analisa a evolução do padrão de especialização comercial, devido a seus efeitos sobre a sustentabilidade de longo prazo do crescimento econômico e a distribuição do ingresso. Demonstra-se que, apesar de que se observa recentemente uma forte expansão das exportações, o padrão de especialização comercial continua refletindo um perfil concentrado em bens primários e manufaturas de baixo nivel tecnológico e conteúdo de emprego. Ou seja, ainda não se produziu uma transformação estrutural na competitividade dos setores não associados aos recursos naturais frente aos que os utilizam de forma abundante. Porém, este fenômeno se insere num contexto que mostra modificações importantes na distribuição dos saldos comerciais com os diferentes sócios, aonde a China começa a adquirir um papel relevante. $O$ trabalho visa, da mesma forma, observar a relação entre tais modificações e a evolução do padrão de especialização

Mots clés: Desenvolvimento econômico, padrão de especialização comercial, vantagem comparativa, abertura comercial, integração regional. 


\section{Introducción}

urante los últimos 15 años, la economía argentina sufrió profundas transfor-

D maciones en materia de política económica. Entre ellas, los procesos de liberalización comercial y financiera, las distintas opciones atravesadas por la integración regional en el ámbito del MERCOSUR, y las situaciones de inestabilidad macroeconómica que culminaron en 2001 con una fuerte devaluación; es decir, con un marcado cambio en los precios relativos. El entorno económico internacional también muestra profundas transformaciones durante los años recientes; entre ellas, el creciente papel asumido por algunas economías asiáticas como las de China e India.

En este contexto es importante analizar el impacto de estas transformaciones sobre la inserción internacional de Argentina, en especial su interacción con otras economías emergentes como Brasil, su principal socio en el MERCosur, y China. Se observa durante esos años una fuerte expansión de las exportaciones que ahora dan lugar a un balance comercial positivo. Sin embargo, también se requiere el análisis de la evolución sufrida por el patrón de especialización, pues ello nos permitirá observar su efecto sobre el comportamiento comercial de los distintos sectores productivos y sobre las relaciones de intercambio con nuestros principales socios comerciales. La relevancia de esta temática se plantea tanto por sus efectos sobre la sustentabilidad de largo plazo de la economía como por el impacto que ejerce sobre los niveles y categorías del empleo; es decir, sobre la calidad de vida de la población.

Como continuación del documento de trabajo, CENES, núm. 4 (Bekerman y Sirlin, 1996), el objetivo del presente artículo es analizar la dinámica y las principales transformaciones sufridas por el patrón de especialización de la economía argentina en el ámbito de sectores y destinos comerciales, durante el periodo 1994-2005. El análisis sectorial incluirá clasificaciones según perfiles tecnológicos y de intensidad laboral, mientras que el de destinos estudiará la evolución del desempeño comercial con Brasil y China. En este periodo destaca el hecho de que el mismo esté signado por un proceso de apertura e integración regional, con dos contextos macroeconómicos marcadamente distintos, definidos por el proceso previo y el posterior al cambio en los precios relativos producidos por la devaluación de 2002. Ello permitirá observar las profundas transformaciones en los niveles sectorial y global que en estas 
distintas etapas del proceso de apertura e integración regional tuvieron lugar en la relación con nuestros principales socios, en especial con Brasil, e identificar posibles casos de desvío de comercio generados con este socio del MERCOSUR.

El análisis está basado en los indicadores de ventajas comparativas reveladas (VCR) y de desempeño comercial (DC) por destino (véase Anexo Metodológico).

El trabajo incluye una discusión teórica acerca de los posibles efectos de los procesos de apertura y de integración regional sobre los patrones de especialización de una economía y del impacto de estos últimos sobre su potencial de crecimiento y bienestar de largo plazo. Asimismo reflexiona sobre cómo las políticas macroeconómicas pueden afectar el patrón de especialización.

Además se analiza la evidencia empírica, así como el periodo en cuestión. Luego se observa la evolución sufrida por el patrón de especialización en el ámbito global, y por socio comercial. Se incluyen conclusiones y dos anexos: uno metodológico y otro estadístico.

\section{Aspectos teóricos acerca de los patrones de especialización}

\section{El debate teórico acerca de su relevancia}

El estudio del patrón de especialización de una economía en el marco del comercio mundial se orienta al análisis de su papel en el esquema de la división internacional del trabajo, incluyendo sus determinantes y sus impactos de mediano y largo plazos sobre los niveles de bienestar de los individuos involucrados.

La pieza teórica es la de las ventajas comparadas de David Ricardo que plantea que una nación se especializará en aquellos sectores donde cuente con costos relativos menores. Pero el verdadero debate surge cuando se trata de explicar cuáles son los factores que determinan esos costos comparativos desiguales y, por tanto, los distintos patrones de especialización, y qué importancia adquieren estos últimos para el crecimiento de los países. Por eso el problema del patrón de especialización internacional ha sido abordado por distintas escuelas teóricas. En Bekerman y Sirlin (1996) se presentan a detalle las principales corrientes de pensamiento que intentan explicar las causas que determinan la configuración efectiva del patrón de especialización de una economía, así como las posibles derivaciones de política que pueden desprenderse de su análisis.

En la primera, la escuela neoclásica, en la versión de los modelos de tipo Heckscher-Ohlin, plantea que el libre comercio lleva a la nación a especializarse en 
aquellos sectores intensivos en los factores relativamente más abundantes. No importa, pues, en qué sectores se especializa una economía en tanto los mismos respondan a la dotación de factores existente.

Si bien estos modelos arrojan predicciones precisas ${ }^{1}$ sobre cuál ha de ser el patrón de especialización de una economía, las divergencias con la evidencia empírica, fundamentalmente a partir de la observación de flujos significativos de comercio intraindustrial, dieron paso a nuevos desarrollos teóricos. Básicamente se trata de las Nuevas Teorías del Comercio Internacional, las Teorías del Crecimiento Endógeno y de las corrientes neoshumpeterianas que fueron dejando de lado a los distintos supuestos del supersimplificado modelo neoclásico tradicional y que coincidieron en señalar que la dotación factorial no constituye el único o aún el principal factor de competitividad. Estos enfoques teóricos incorporan importantes aspectos ligados a la existencia de economías de escala, de factores reproducibles con rendimientos no decrecientes y efectos derrame entre industrias y de diferencias internacionales en materia de conocimiento y capacidad tecnológica.

A partir de estas teorías surgen nuevas fuentes de ventajas comparadas que plantean una diferenciación entre los distintos sectores productivos en los que puede especializarse una nación. Las fuentes de ventaja comparada de los sectores imperfectamente competitivos, donde predominan las economías de escala, son diferentes de aquellas correspondientes a los sectores en que los rendimientos constantes son la regla. De la misma manera, serán diferentes para aquellos sectores que insumen (y producen) altos niveles de trabajo calificado con respecto al resto de los sectores. La ventaja comparada de los sectores más modernos, a su vez, depende mucho más de la capacidad tecnológica que la de aquellos sectores maduros donde predominan tecnologías ampliamente difundidas.

Por otra parte, la captación de los aspectos dinámicos vinculados con los patrones de especialización permite deducir la relevancia de éstos en toda estrategia de crecimiento de mediano y largo plazos. Mientras que algunos sectores sólo ofrecen una retribución normal a sus factores, otros presentan rentas monopólicas o schumpeterianas, brindan externalidades o dan lugar a tasas de crecimiento de la productividad (y, por tanto, del ingreso per capita) mayores.

En la medida en que el patrón de especialización afecta la tasa de crecimiento de la productividad de una economía, puede repercutir en la sustentabilidad del crecimiento mismo. Fanelli (2000) resalta tres aspectos esenciales en relación con este

1 Al ser esto una virtud desde el punto de vista epistemológico por su mayor contenido empírico. 
tema. En primer lugar, en concordancia con lo señalado, plantea que una economía especializada en recursos naturales tiende a desarrollar retrasos en la evolución de su productividad a causa de lo que se conoce como enfermedad holandesa, lo cual se traduce en incapacidad para el desarrollo de encadenamientos productivos y procesos de aprendizaje. ${ }^{2}$ En segundo término menciona que una economía especializada en recursos naturales experimentará una mayor varianza en sus ingresos por exportaciones, y dado el nivel de imperfecciones en los mercados de capitales en países en desarrollo dicha varianza se traduce en volatilidad macroeconómica. Finalmente, observa que la acumulación de capital físico se ve sumergida en una dinámica volátil, debido a que la misma se produce, en gran parte, mediante la importación de bienes de capital y su financiamiento queda precisamente sujeto a la señalada volatilidad de las exportaciones y de los fondos prestables internacionales.

Es decir, a diferencia del enfoque neoclásico y en la medida en que consideran que para ciertos sectores los beneficios sociales suelen exceder a los beneficios privados (tal como ellos se perciben a partir de las señales del mercado), existen distintos enfoques teóricos alternativos que plantean que el patrón de especialización puede tener un fuerte impacto sobre el sendero de crecimiento de una nación. Por otro lado, ese impacto lo convierte en un determinante fundamental de la sustentabilidad de una economía en el largo plazo.

Efectos de la apertura y de la integración regional

sobre los patrones de especialización de un país periférico

En esta sección se presentan algunos de los efectos teóricamente esperables, tanto de un proceso de apertura de una economía como de integración regional.

Para los autores neoclásicos, la apertura mejorará la retribución de los factores abundantes de un país, a costa de aquellos previamente favorecidos por la protección. Sin embargo, las ganancias de unos serán ampliamente mayores a las pérdidas de los segundos, por lo que se puede afirmar que (mediando las políticas redistributivas correspondientes) la apertura incrementará el bienestar. Al mismo tiempo tendrá un efecto indiscutiblemente positivo sobre los patrones de especiali-

2 Sin embargo, debemos señalar que en la actualidad existe un debate acerca del desarrollo tecnológico en el sector primario. Los argumentos en favor de los mayores niveles de productividad de la industria se ven relativizados debido a la conformación de complejos agroindustriales donde la innovación, tanto de procesos (Rama, 1998) como de producto (Wilkinson, 1998), se lleva a cabo a un ritmo intenso. 
zación debido a dos razones principales: (i) el nivel estático, porque mejorará la asignación de los recursos y eliminará las ineficiencias derivadas de los mercados protegidos, y (ii) el nivel dinámico, porque desarrolla los procesos de aprendizaje y de cambio tecnológico.

En contraposición a los modelos neoclásicos, en los que el principal motor del crecimiento es el cambio tecnológico externo, los teóricos neoschumpeterianos y de la escuela del crecimiento endógeno sostienen que si bien las ganancias estáticas del comercio han sido claramente determinadas en la teoría del comercio internacional, muy poco se ha establecido acerca de los efectos dinámicos de largo plazo, como el aumento de la productividad y del progreso tecnológico. Por tanto, no se pueden establecer conclusiones universales acerca de los efectos de la apertura sobre la situación de las ventajas comparativas de un país y sobre su crecimiento de largo plazo (Grossman y Helpman, 1991).

Es importante determinar si la apertura del comercio tiene lugar entre naciones con dotaciones de factores y tecnología similares o si existen fuertes asimetrías en cuanto a tamaño, acumulación de conocimientos y ventajas comparativas ya adquiridas. En este último caso, el país más pequeño, o más atrasado tecnológicamente, puede enfrentar una intensa competencia externa que reduzca la ventaja de sus innovaciones en aprendizaje y lo aleje aún más de un proceso de catching up (Grossman y Helpman, 1991). Es decir, cuando más asimétrica es la ventaja comparativa entre dos pueblos, mayores son las posibilidades de que el país más atrasado tienda a aumentar su especialización en aquellos sectores en los que presentaba las ventajas comparativas previas más fuertes. De este modo, cuando la apertura se produce con una nación tecnológicamente más avanzada que no dispone de una dotación de recursos naturales que sea competitiva con el país periférico, puede esperarse que el patrón de especialización de este último se oriente claramente hacia un proceso de primarización.

Uno de los problemas que puede derivarse de esta situación - y que es altamente relevante para explicar el caso argentino- ocurre cuando existe una complementariedad tecnológica entre los recursos naturales y el factor capital. Es posible, entonces, que el patrón de especialización se configure como capital intensivo, con baja intensidad en la utilización del factor trabajo (Ffrench-Davis, 1990). El efecto de ello es un nivel de salario de equilibrio extremadamente bajo o una tasa de desempleo elevada. De hecho, la incapacidad del sector primario para generar empleo parece verse agravada en la actualidad en el caso argentino por la utilización de tecnologías transgénicas, fundamentalmente ahorradoras de mano de obra (Rodríguez, 2004). 
Un problema adicional para un país periférico se presenta cuando la apertura tiene lugar con otro más avanzado tecnológicamente y que, al mismo tiempo, dispone de una dotación de recursos naturales tal que dificulta su desempeño comercial, aun en los sectores en lo que presenta ventajas comparativas con los otros destinos. En este caso el resultado podría significar un déficit bilateral muy significativo para el país periférico, dada su necesidad de aprovisionamiento de insumos y manufacturas sofisticadas, en especial cuando mayor es la dificultad que dicha economía presenta en los mecanismos de ajuste vía precios y salarios. Ello puede tender a consolidar un tipo de comercio triangular o a profundizar un saldo negativo de su balance comercial.

De forma paralela al efecto que en sí puede tener un patrón primarizado sobre el crecimiento, su sustentabilidad y el nivel de vida de la población, surge un factor adicional del hecho de que los patrones comerciales basados en productos primarios se asocian históricamente a una estructura exportadora no diversificada. Agosin (2006) argumenta que la diversificación de las exportaciones es un síntoma de que ciertos fenómenos positivos han tenido lugar, ${ }^{3}$ entre ellos la acumulación de habilidades, learning by doing, externalidades pecuniarias positivas que surgen de la producción de insumos no transables clave, externalidades tecnológicas en el mercado de trabajo e innovación tecnológica.

Cabría considerar el impacto sobre los patrones de especialización de un proceso de apertura con naciones que detentan un grado de desarrollo tecnológico similar, lo que podría tener lugar en los casos de integración regional entre países menos desarrollados como es el caso del MERCosur. En este contexto, la teoría neoclásica plantea que el patrón de especialización intrarregional tenderá a ser más capital intensivo que el patrón de especialización global de los pueblos en cuestión. A partir de allí, se concibe que un proceso de integración será beneficioso cuando estos sesgos asignativos (que reflejan un desvío de comercio) son más que compensados por el mejor aprovechamiento de las ventajas comparadas genuinas de cada nación (que son las que están detrás de la creación de comercio) (Viner, 1950).

Sin embargo, distintos trabajos ponen énfasis en las limitaciones de análisis de carácter estático como el de Viner. En Devlin y Estevadeordal (2001) se plantea que en aquéllos se destacan los costos en términos de desvío de comercio sin tomar en

3 De acuerdo con este autor, si bien desde distintas teorías del comercio internacional se han destacado las ventajas de la especialización, es un hecho empírico que todas las economías altamente especializadas son pobres (Agosin, op. cit., p. 3). 
cuenta la existencia de posibles beneficios potenciales resultantes de una reducción paralela de aranceles internos y externos, como la introducción de competencia, la captación de nuevas inversiones y el desarrollo de procesos de externalidades, ligadas —entre otros aspectos- a la configuración de un mercado ampliado.

Estos impactos positivos en términos de eficiencia dinámica resultantes del comercio entre países en desarrollo han sido también mencionados por Amsden (1986), quien resalta su carácter intensivo en el trabajo calificado (skill intensive) y su potencialidad de profundizar los procesos de aprendizaje.

Podría derivarse, entonces, que si los países que inician un proceso de integración detentan un grado de desarrollo similar y existe una relativa armonización de políticas que elimine las diferencias regulatorias previas, es posible generar una especialización de carácter intraindustrial que permita a dichos países ganar capacidad de escala para exportar bienes tecnológicamente más avanzados, lo cual no sería posible mediante un proceso de apertura unilateral. Sin embargo, resulta necesario que no existan grandes diferencias o asimetrías en el ámbito de las regulaciones, pues de lo contrario podrían generarse ventajas comparativas en favor de aquellas naciones que ofrezcan incentivos mayores, lo que podría producir guerras de incentivos que llegaran a debilitar al proceso de integración o reproducir a escala regional un desempeño comercial propio de las relaciones Norte-Sur (Bekerman y Sirlin, 1996).

\section{El papel de las políticas macroeconómicas ${ }^{4}$}

Los efectos que se esperan de los procesos de apertura e integración sobre los patrones de especialización serán afectados adicionalmente por las políticas macroeconómicas que los acompañen, por medio del comportamiento de dos variables clave: la evolución del nivel de actividad y del tipo de cambio real. ${ }^{5}$

En este sentido, la evolución del nivel de actividad puede incidir sobre la evolución del indicador de ventajas comparativas que se utiliza en este trabajo (vinculado con la contribución de cada sector al balance comercial), a partir de su impacto sobre el comportamiento de las importaciones y de las exportaciones. Un nivel más alto de

4 En cuanto al papel de las políticas microeconómicas, un análisis para el caso argentino del conjunto de políticas comerciales, industriales y tecnológicas se presenta en Bekerman y Sirlin (1994).

5 En Heymann y Navajas (1998) puede encontrarse evidencia empírica según la cual las importaciones intra-Mercosur son más sensibles a variaciones del Producto Interno Bruto (PIB) del país importador que del tipo de cambio real del mismo. La experiencia argentina reciente, de hecho, no permite rechazar esta hipótesis. 
actividad generará una mayor presión sobre las importaciones, especialmente en aquellos sectores que muestran más elasticidad de las mismas con respecto al producto. En cambio, una situación recesiva producirá el efecto contrario. Las exportaciones pueden verse también afectadas por variaciones en el producto doméstico, y, sobre todo, por las de los países socios.

Por otro lado, en la medida en que se registre un tipo de cambio sobrevaluado se genera una reducción de los niveles de competitividad del conjunto de los sectores productivos; y en asociación con el proceso de apertura, puede determinar una agudización de las desventajas comparativas en aquellos sectores de bienes transables que ya se encontraban —en virtud de la mayor productividad comparativa del sector primarioen esa situación. Sin embargo, cabe destacar que la situación inversa no tiene necesariamente consecuencias simétricas. Es decir, un tipo de cambio real subvaluado no siempre implica una mejora en las ventajas comparativas en los sectores no primarios, pues no es condición suficiente para lograr una competitividad industrial sustentable, sea por cuestiones estructurales o por "incertidumbre macroeconómica" (Carrera, 2006).

En las próximas secciones trataremos de ver — con los indicadores de ventajas comparadas reveladas y desempeño comercial— si el impacto de la apertura y la integración sobre el patrón de especialización de la economía argentina presentan alguna relación con las posiciones planteadas en este aparatado. Al respecto, tanto el análisis del patrón de especialización global como el desempeño comercial con los distintos socios involucrarán dos subdivisiones: el modo de observar separadamente las transformaciones recientes provocadas por el desarrollo del proceso de apertura y la integración regional en un contexto de subvaluación del tipo real de cambio, en contraposición con el contexto previo de sobrevaluación del mismo.

\section{El patrón de especialización argentino}

\section{El periodo bajo análisis}

El periodo de análisis abarca desde 1993 hasta el primer semestre de 2005. Nuestra evaluación sobre los cambios que tuvieron lugar en los patrones de especialización a lo largo del mismo tomará en cuenta los factores considerados en la sección anterior, es decir, tanto los cambios estructurales ligados con los proceso de apertura y de integración como la evolución de las dos variables macroeconómicas clave: el tipo de cambio y el nivel de actividad. 
Una primera etapa está signada por un sistema de currency board, que dio lugar a un proceso de creciente apreciación real de la moneda doméstica. Incluye de este modo la recesión que tuvo lugar durante 1995 como consecuencia de la crisis mexicana, para mostrar una rápida recuperación del PIB que se extiende hasta el segundo trimestre de 1998 (véase la gráfica $1^{6}$ ). La devaluación mexicana hacia fines de 1994 muestra el inicio de una serie de perturbaciones externas que se prolongan con el shock de los países asiáticos en 1997 y el de Rusia en 1998, crisis caracterizadas por el colapso de los sistemas cambiarios y la contracción del PIB (Chudnovsky et al., 2003). En respuesta a la crisis mexicana, los flujos internacionales de capital muestran una caída importante en 1995, pero se recuperan rápidamente para continuar su crecimiento hasta 1998, momento en que comienza un periodo de salida de capitales de creciente magnitud.

En 1995 se pone en marcha la plena vigencia de los acuerdos del MERCosuR a partir del establecimiento de libre comercio intrazona y del Arancel Externo Común. ${ }^{7}$ Esto determina una creciente interacción con la economía de Brasil y un impacto creciente sobre la economía argentina de ciertas variables macroeconómicas de ese país, como su nivel de actividad y tipo de cambio.

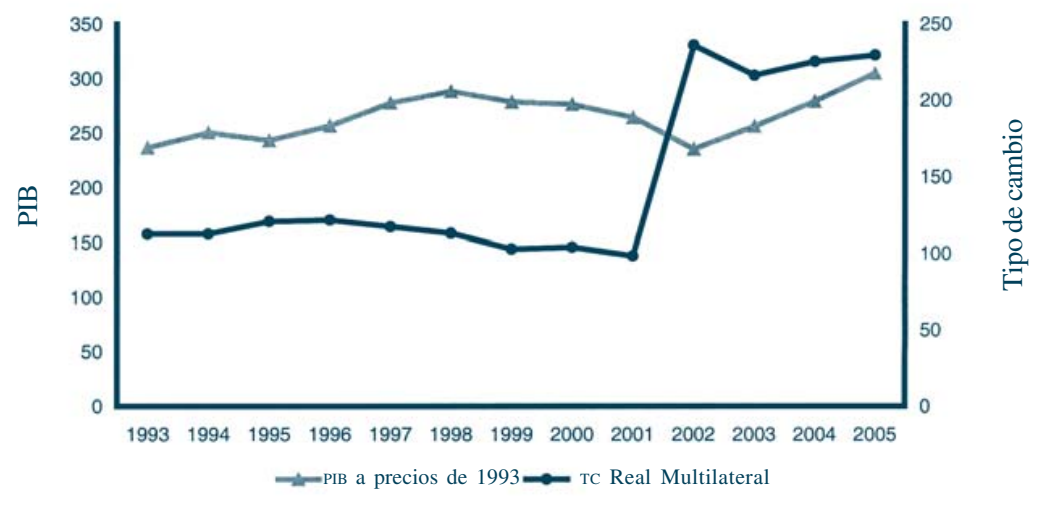

Gráfica 1. Evolución del producto y del tipo de cambio.

Elaboración propia con base en datos del INDEC y del Banco Central de la República Argentina. Las exportaciones al MERCosur pasaron de 2000 MM en 1991 a 9411 MM en 1998, es decir, $30 \%$ de las exportaciones argentinas de este último año. En el primer semestre de 2005, 15\% de las exportaciones argentinas tuvo ese destino, y 36\% de las importaciones, ese origen. 
Dicha interacción estuvo acentuada debido a la ya mencionada mayor vulnerabilidad de la economía argentina en virtud de su regla de política cambiaria.

La caída en el nivel de actividad desde 1998 genera una reducción en el de importaciones y en el resultado del balance comercial que se convierte en positivo a partir de 2000 .

La etapa recesiva de la economía culmina con la devaluación de principios de 2002. A partir de 2003, la economía presenta un crecimiento anual promedio positivo. En el plano internacional, 2002 podría incluirse en la etapa de predevaluación, pues tanto el aumento de la liquidez internacional como otros hechos relevantes (e. g., la apreciación del real) son procesos que comienzan en 2003. Sin embargo, si bien este año es de crecimiento negativo para Argentina, la decisiva influencia (al menos en el corto plazo) de la devaluación en el comercio y en la sustentabilidad del crecimiento inducen incluirlo junto con el periodo 2003-2005.

La elevación del tipo de cambio real responde a un aumento de los precios internos, oficialmente del orden de 70\%, que no llega a cubrir la devaluación nominal del peso de $200 \%$, otorgando en el corto plazo una mayor competitividad a la producción doméstica. En virtud de la depreciación real, a partir de 2003 se inicia la recuperación con eje en las exportaciones, que, a dólares corrientes, superan su participación en el producto en más del doble, al pasar de $12 \%$ en 2001 a $25 \%$ en 2005. En paralelo a esta evolución son reinstauradas las retenciones a las exportaciones de productos primarios.

\section{Patrón de especialización global}

Características generales

Para analizar el comportamiento del patrón de especialización argentino utilizaremos el indicador de Ventajas Comparadas Reveladas (VCR). ${ }^{8}$

Como puede observarse en el cuadro 1 que aparece en el Anexo Estadístico, Argentina muestra un patrón de especialización claramente dual. Las fuentes de ventajas comparati-

s Como se explica en el Anexo Metodológico, el indicador de vcR es el balance comercial sectorial normalizado. Es decir, se toma la diferencia entre exportaciones e importaciones de cada sector y se ajusta dicho valor en función del resultado, ya sea déficit o superávit, que muestra el balance comercial total. Las ventajas (valores positivos) o desventajas (valores negativos) se miden en milésimos del comercio total de cada año. De esta manera el indicador de VCR puede fluctuar entre -500 y 500 milésimos del comercio total, siendo los valores extremos los correspondientes a una situación de especialización completa (es decir, no existe comercio intrarrama). 
vas radican en la producción de bienes primarios, en las manufacturas de origen agropecuario (MOA) y en el sector energético. Como contraparte de ello, la producción de manufacturas de origen industrial (MOI) presenta un alto nivel de desventajas comparadas.

En el ámbito de los productos primarios, se destacan las ventajas comparativas que presentan los cereales y oleaginosas, y en segundo término los pescados y mariscos sin elaborar junto con las legumbres y frutas frescas.

En cuanto a las MOA — por un lado sobresalen alimentos para animales y aceites y grasas; por otro, en orden de magnitud, cueros y carnes - han resultado los de mejor desempeño relativo.

En el marco de las MOI destacan, por sus fuertes desventajas comparativas, las maquinarias y aparatos y la industria química (fundamentalmente productos medicinales y farmacéuticos), seguidas por el material de transporte.

Por otra parte, al discriminar las MOI según el perfil tecnológico (véase el cuadro 2), las clasificadas como industrias nuevas presentan la mayor desventaja comparativa y, a su vez, dentro de éstas, las de media y alta tecnología. No obstante, las industrias de insumos básicos y tradicionales también reflejan desventajas comparativas, aunque de mucha menor magnitud en términos relativos.

Finalmente, en el agregado de producción manufacturera (MOA y MOI) puede observarse que, en materia de intensidad laboral, el patrón de especialización argentino presenta también fuertes asimetrías. Las únicas actividades que exhiben ventajas comparativas son las que presentan baja intensidad laboral, mientras que ocurre lo contrario con las actividades caracterizadas por medias o altas intensidades laborales (véase cuadro 3).

Cambios recientes en el patrón

de especialización global

A partir de la recesión que inicia en 1998 se observa una tendencia a la atenuación del patrón primarizado que venía registrándose, aunque, como veremos a continuación, no se trata de una reversión del mismo. Es una tendencia transitoria, determinada por una menor intensidad de importación de ciertos bienes en los que la economía tiene una desventaja comparativa, resultante de la señalada recesión que se extiende hasta 2002. Involucra, sobre todo, a material de transporte y maquinaria y aparatos, lo que da lugar, durante esos años, a variaciones positivas en los indicadores de VCR de las MoI.

Con la recuperación que inicia en 2003 esta tendencia se revierte y se advierte una nueva profundización del carácter dual del patrón de especialización 
argentino. Se aprecia entonces un proceso de primarización por un aumento en las desventajas comparativas de las MOI (liderado por maquinaria y aparatos y, en menor medida, material de transporte) y una recuperación de las VCR en MOA y productos primarios. Hacia 2005 las VCR en productos primarios, las MOA y las MOI se encontraban en niveles prácticamente idénticos a los de 1998, cuando se iniciaba el largo proceso de contracción del PIB. Esto podría implicar que la evolución del nivel de actividad global (PIB) resultó ser una variable decisiva en la configuración de las tendencias presentadas por el patrón de especialización durante el periodo considerado. Sin embargo, no puede dejarse de lado el papel del comportamiento de la demanda internacional de productos primarios alentada por la expansión de la economía china.

Durante los últimos años los productos primarios son los que experimentaron el mayor crecimiento en sus ventajas comparativas, impulsado por los rubros de semillas y frutas oleaginosas, cereales y legumbres y frutas frescas. Del lado de las MOA resulta notable la recuperación de carnes, aceites y grasas y alimentos para animales, estos dos últimos considerados los rubros de mayor peso en las MOA a lo largo de todas las etapas. Esta evolución de las MOA, de baja intensidad laboral, muestra un patrón de especialización con una clara tendencia a requerir menos mano de obra. Al respecto, resulta destacable que las industrias de media y alta intensidad laboral resultaron las más afectadas, en materia de balance comercial, por la devaluación.

En el caso de los productos energéticos, luego de alcanzar un nuevo piso en 2002, se mantienen inalterados por limitaciones de la oferta local.

\section{Desempeño comercial según los principales socios}

En este apartado analizaremos cómo evolucionó la participación de los principales socios comerciales, a saber: Brasil y China. Como se puede apreciar en la gráfica 2, estos socios concentraban $24 \%$ en 1993, que llegó a representar un tercio del comercio total hacia 2005. Asimismo, la gráfica refleja una ganancia en la participación brasileña durante el periodo 1993-1998, con picos en 1998 y 2000, para luego caer hasta 2003. La participación de Estados Unidos (EU) ha sido relativamente constante a lo largo del periodo de análisis, mientras que la Unión Europea (UE) ha perdido peso en paralelo al aumento del comercio con China y con el resto de los destinos. Dentro de estos últimos, se destaca en 2004 la participación de Chile (7.5\% del total) y de los 
países del sureste asiático $(3.65 \%)$, México (3.2\%), Paraguay (1.6\%) y Uruguay $(1.6 \%)$.

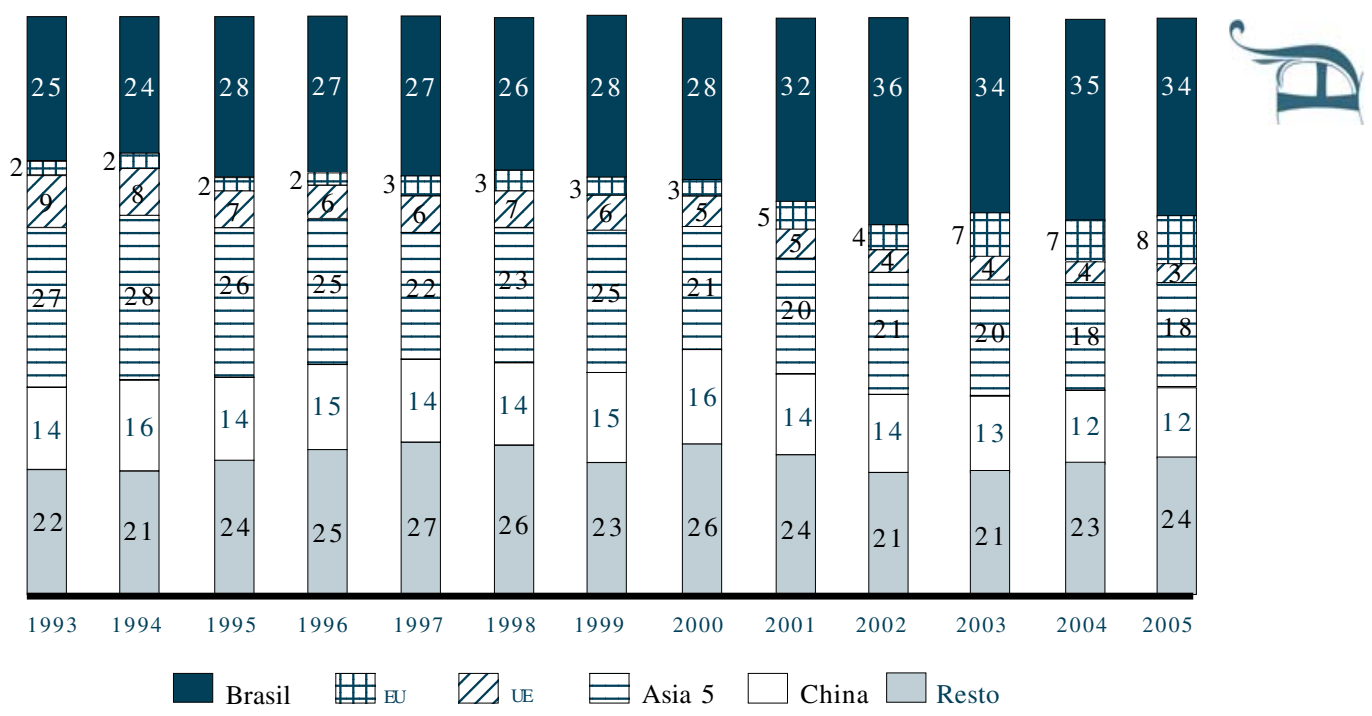

Gráfica 2. Participación relativa (\%) de los principales socios comerciales en el comercio argentino total $(\mathrm{X}+\mathrm{M})$.

\section{Desempeño comercial por grandes rubros y socios comerciales}

A continuación se describe la situación que presentan las ventajas comparativas por grandes rubros, con respecto a los distintos socios comerciales, utilizando el indicador de desempeño comercial (DC). ${ }^{10}$ Dejamos para un apartado subsiguiente el análisis detallado del patrón de especialización integral con los principales socios emergentes.

9 Corea del Sur, Hong Kong, Japón, Singapur y Taiwán.

10 Al igual que el indicador de vCR, el indicador de DC se explica detalladamente en el Anexo Metodológico. Como síntesis, puede decirse que el indicador de DC son balances comerciales bilaterales de cada sector, correspondientes a una situación de equilibrio comercial global (no bilateral); es decir, ponderados por el comercio global. Un signo positivo (negativo) indica que un determinado país tiene, relativamente a su participación en el comercio total, un déficit comercial menor (mayor) o un superávit comercial mayor (menor) que el resto de las naciones. A su vez, lo que lo hace comparable entre socios es el hecho de estar ponderado por el comercio bilateral. 
En materia de productos primarios, la ventaja comparativa se verifica principal y significativamente con la UE a lo largo de todo el periodo de análisis; con Brasil hasta el año 2001; y con China desde fines de la década pasada. Con Eu, en cambio, la ventaja comparativa es muy reducida o por periodos inexistente.

En el caso de las MOA, también la uE es el socio con el que mejor desempeño se registra (un promedio de 189 milésimos del comercio total). Con eu se aprecian ventajas comparativas, aunque de menor magnitud. En relación con China, la importancia ha ido declinando desde 1997 hasta 2001 para recuperarse a partir de entonces. Brasil, en cambio, es dentro de los destinos considerados el que presenta ventajas comparativas de menor magnitud, o casi nulas en ciertos periodos, situación que se profundiza durante los últimos años.

En cuanto a las MOI, dentro de una situación de fuertes desventajas comparativas, el principal quebranto histórico se presenta con EU, seguido por la UE y China. Con Brasil, el menoscabo es mucho menor. Sin embargo, son notables los cambios que se producen en la evolución de los indicadores. Por un lado, el proceso de apertura y desregulación tiene un efecto negativo en el desempeño con EU y la UE, mientras que con Brasil, mediante un efecto atribuible al proceso de integración, se observa una importante mejora hasta 1999, momento que coincide con la devaluación brasileña y el comienzo de etapas contractivas en el nivel de actividad de Argentina y Brasil. A partir de allí se observa un deterioro en la relación con Brasil hasta el punto en que para el promedio del periodo 2002-2005 el DC con ese país en las MOI se hace mayor que el que se registra con la UE.

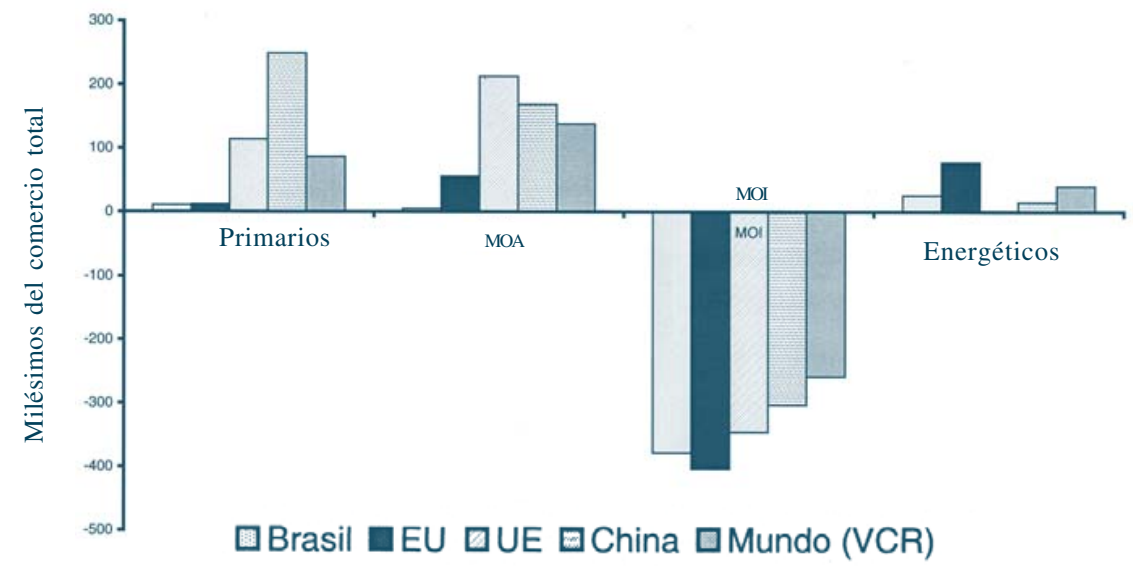

Gráfica 3. DC y VCR promedio 2002-2005, principales socios comerciales. 
Finalmente, en productos energéticos, el desempeño sostenidamente favorable, si bien volátil, está explicado por el intercambio con EU y Brasil, con un empeoramiento en este último caso a partir de 2002.

La gráfica 3 muestra los valores promedio registrados durante el periodo 20022005 (primer semestre), por los indicadores de ventajas comparativas reveladas (en el nivel global) y de desempeño comercial (por destinos).

\section{Desempeño comercial por socio}

según intensidad laboral y perfil tecnológico

Al analizar el desempeño comercial promedio por socio según la intensidad laboral, resulta llamativo el fuerte deterioro que presentan las manufacturas de intensidad laboral media y alta con Brasil (véase la gráfica 4). Mientras en el periodo 1993-2002 el desempeño con este socio es el mejor dentro del grupo analizado, a partir de 2003 pasa a ubicarse en el último lugar, muy lejos del estado prácticamente neutral que había alcanzado hacia 1997-1998.

Por el contrario, con el resto de los socios comerciales se verifica una tendencia a reducir la desventaja comparativa en el rubro de intensidad laboral media y alta, luego del piso alcanzado hacia el bienio 1997-1998. De hecho, los socios con los que mayores ganancias se registran resultan ser China y Estados Unidos como puede verse en la gráfica 4.

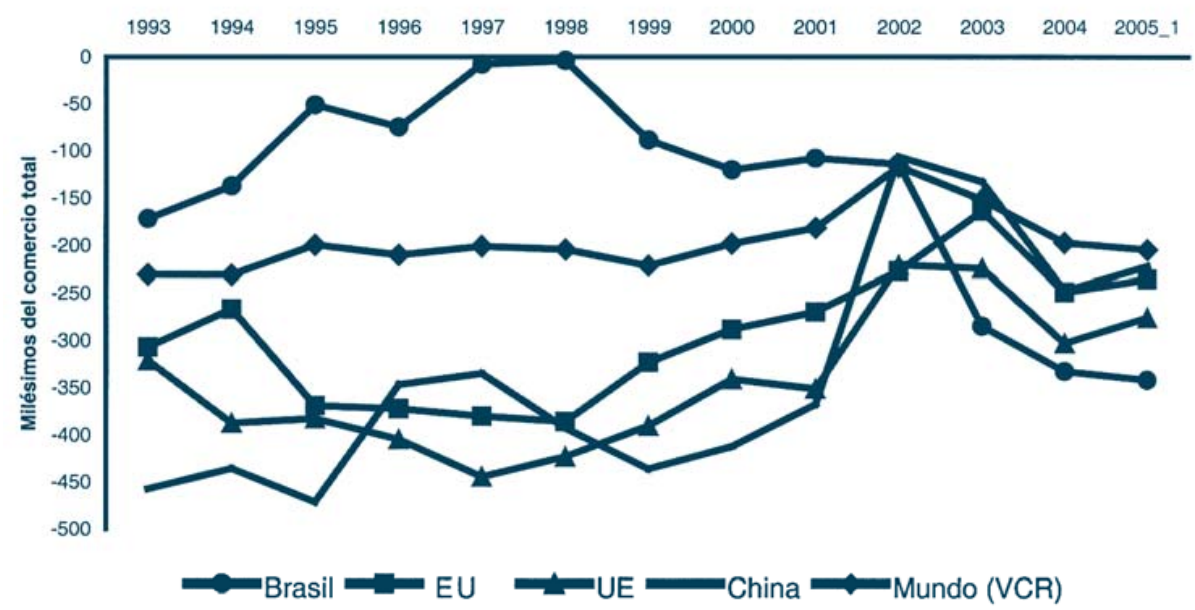

Gráfica 4. Evolución DC y VCR manufacturas (MOA y MOI) de intensidad laboral media y alta, principales socios comerciales. 
Respecto al perfil tecnológico de las relaciones comerciales con los principales socios, en industrias nuevas de alta tecnología a partir de 2002 se produce, también, un deterioro con Brasil, aunque con un nivel menos pronunciado. Los cambios recientes parecen señalar una tendencia a la reducción de la desventaja comparativa con EU y China (véase gráfica 5).

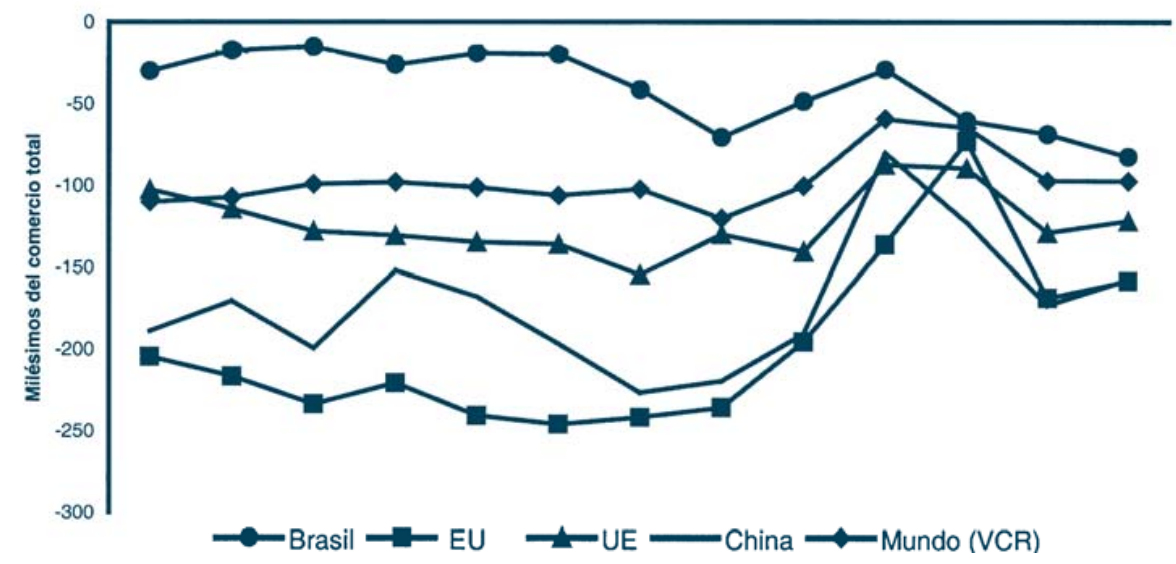

Gráfica 5. Evolución DC y VCR industrias nuevas de altas tecnologías, principales socios comerciales.

\section{Desempeño comercial con Brasil}

En esta sección realizaremos un análisis del patrón de especialización por destinos utilizando el indicador de desempeño comercial (véase nota 9 y Anexo Metodológico).

\section{- Características generales}

El patrón de especialización con Brasil, al igual que a escala global, puede ser calificado como primarizado, ya que el DC favorable se registra al nivel de los productos primarios y energéticos, al contrario con las MoI. Sin embargo, existen al menos dos rasgos generales que distinguen históricamente al patrón de especialización desarrollado con Brasil con respecto al global: una mejor performance relativa de las MOI y un DC muy inferior de las MOA (véase cuadro 4).

En el nivel de los productos primarios se destacan los cereales y, en menor medida, las legumbres y frutas frescas. Por otro lado, es remarcable el DC nulo de las semillas oleaginosas y el signo negativo de los minerales en bruto. 
$\mathrm{Al}$ interior de las MOA se distingue el pobre desempeño de aceites y grasas y, sobre todo, de alimentos para animales, ambos muy importantes en el patrón global. Los productos de molinería y los lácteos llegaron a presentar, en cambio, periodos de mejor desempeño que los correspondientes al comercio con el mundo.

En el caso de las MoI, se observan históricamente dos diferencias importantes con respecto al patrón global: un signo negativo muy relevante en el sector de metales y sus manufacturas y un DC menos desventajoso en maquinaria y aparatos.

- Cambios recientes en el patrón de desempeño comercial con Brasil

A partir de la devaluación brasileña y, sobre todo desde 2002, se consolidan signos de alarma en la relación comercial bilateral mediante una marcada reducción en el DC positivo que presentaban los productos primarios, las MOA y energéticos, y una agudización en las desventajas que muestran las MoI. En el caso de estas últimas, parecería observarse la existencia de un desvío de comercio en ciertos rubros en favor de este socio comercial, en detrimento de las importaciones del resto del mundo.

Dentro de los productos primarios es notorio el deterioro en el DC que presentan durante los últimos años los rubros de cereales, algodón sin elaborar y mineral en bruto. Al interior de las MOA se observan, también, tendencias declinantes en los subsectores que mostraban un mejor desempeño relativo como productos de molinería y lácteos.

Con respecto a las MOI, los subsectores que mayor deterioro muestran son material de transporte, maquinaria y aparatos y metales y sus manufacturas. También la industria química se vio fuertemente afectada a partir de 2002-2003. El corolario del comportamiento de las mor es una caída en el desempeño de las industrias nuevas — que habían alcanzado un pico en 1998, sobre todo de media tecnología—y una importante caída en los productos de intensidad laboral media. Ello, a raíz de los desempeños de material de transporte y de metales y sus manufacturas.

En suma, el desempeño comercial argentino en las Mol respecto de su socio comercial vecino muestra una marcada tendencia negativa iniciada en 1998, cuando aún no había tenido lugar la devaluación brasileña — por parte de ninguno de los dos socios-, e incluso con una economía argentina que, en virtud de la depresión interna, contrajo sus importaciones, en especial en dicho rubro. Esto puede presentarse como evidencia de la existencia de políticas de índole microeconómica del lado de Brasil que permitieron un desarrollo genuino y duradero de estos sectores. El caso de los terminales móviles, presentado en el recuadro 1, es ilustrativo de este tipo de políticas. 


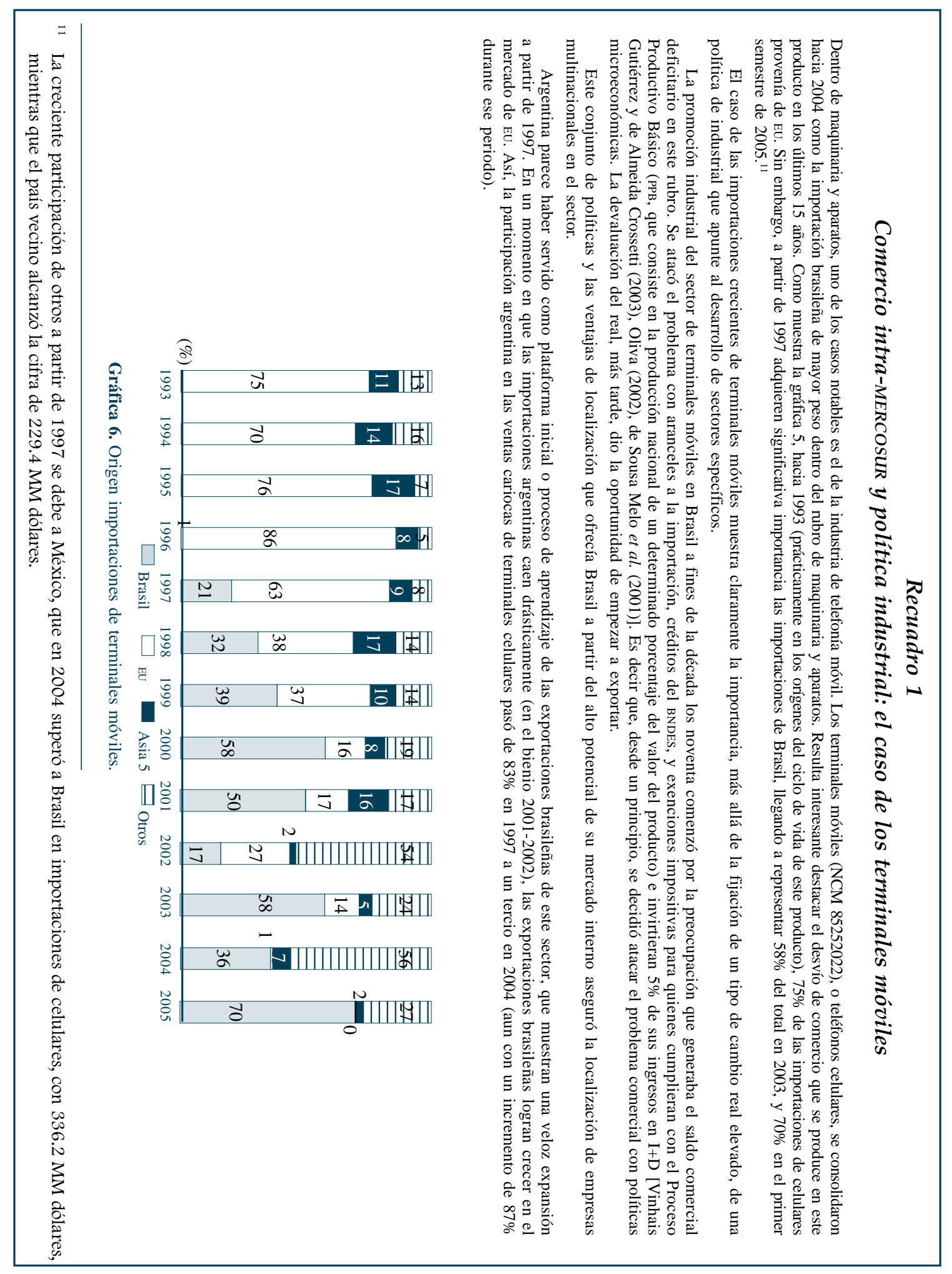




\section{Desempeño comercial con China}

\section{- Características generales}

La importancia que adquiere este socio comercial en los últimos años se refleja en el hecho de que la participación de este país en las exportaciones argentinas pasa de $1.2 \%$, en 1993, a $9.4 \%$ en el primer semestre de 2005.

El fortalecimiento de los lazos comerciales entre ambas economías se da en el marco de un desempeño comercial positivo en las MOA y en productos primarios y negativo en las MOI. En cuanto a las MOA, aceites y grasas son el rubro de mayor importancia a lo largo de todo el periodo, mientras que la creciente ventaja en productos primarios se basa, esencialmente, en semillas y frutas oleaginosas. La desventaja estructural con China en las mor se localiza en maquinaria y aparatos y, en menor medida, en textiles y en la industria química. Se observa una desventaja comparativa en ciertas industrias tradicionales (impresos, joyas y objetos de orfebrería y artefactos y accesorios sanitarios, etc.) y nuevas (véase cuadro 5).

\section{- Cambios recientes en el DC con China}

En la evolución del patrón de especialización comercial con este socio, lo más destacable es la impresionante mejora en el desempeño comercial global.

Esto se genera, a partir de la devaluación de 2002, de un mejor desempeño de los productos primarios y de las MOA, así como de una reducción en el DC negativo que presentaban las MoI. En el caso de los productos primarios se observa un avance importante en semillas y frutas oleaginosas, mientras que en el resto de los productos primarios las ventajas resultan insignificantes. Algo similar ocurre con las MOA, donde aceites y grasas se recuperan del piso alcanzado en 2001.

Con respecto al buen desempeño de las MoI, el mismo se asocia a la evolución de maquinaria y aparatos y a la de consolidación del sector textiles, que en una década redujo a cero una brecha que era inicialmente de magnitudes similares a las de maquinaria y aparatos.

\section{Conclusiones}

Nuestro análisis del comercio exterior argentino —a partir de la utilización de los indicadores de Ventaja Comparativa Revelada y de Desempeño Comercial—arroja 
un conjunto de resultados que en algunos casos tienden a confirmar hipótesis planteadas en la primera parte de este artículo, mientras que en otros ofrecen nuevos elementos de juicio que son muy relevantes para comprender la evolución reciente de la inserción comercial de Argentina.

Como ya fue señalado, se observa recientemente una fuerte expansión de las exportaciones argentinas en el ámbito global que hicieron posible sostener un balance comercial positivo durante los últimos cinco años. Sin embargo, la evolución sufrida por el patrón de especialización comercial (medido con los indicadores señalados) muestra un perfil que se mantiene concentrado en bienes primarios y manufacturas de bajo nivel tecnológico y poco intensivas en empleo. Se observa la persistencia de una estructura claramente dual, con fuertes ventajas comparadas en productos primarios y fundamentalmente las MOA, y manifiestas desventajas en las MOI. Si bien este último rubro muestra un marcado aumento de sus exportaciones durante los dos últimos años, sigue presentando un déficit comercial significativo que explica la persistencia de las desventajas señaladas.

Podría señalarse, entonces, que hasta el presente la fuerte depreciación del peso que tuvo lugar a partir de 2002 dio lugar a una importante expansión de las exportaciones pero no generó aún una transformación estructural en la competitividad de los sectores no asociados a los recursos naturales vis-à-vis aquellos que los utilizan en forma abundante. Sin embargo, debe señalarse que el déficit comercial que muestran hoy las mor es mucho menor al existente en los años previos a la recesión. Como el producto bruto argentino ya recuperó los niveles anteriores a la crisis, cabe preguntarse si su expansión exportadora no estaría mostrando nuevas perspectivas vinculadas con una transición hacia un patrón más diversificado de comercio exterior. Creemos que el fortalecimiento de esa posible transición requiere la profundización de estrategias productivas que avancen más allá de los efectos derivados de la devaluación.

La definición de dichas estrategias se vuelve especialmente relevante ya que, como fue señalado en la sección teórica, la persistencia de una inserción poco diversificada podría generar en el largo plazo limitaciones sobre la tasa de crecimiento de la productividad de la economía y sobre el grado de sustentabilidad de dicho crecimiento y de los niveles de empleo. Esto podría verse agravado por el hecho de que, en el caso de las MOA, la especialización se da en industrias con un bajo grado de complementariedad con el factor trabajo, lo que se ve corroborado por el hecho de que, dentro del agregado de producción manufacturera (MOA y MOI), las actividades que exhiben ventajas 
comparativas son las que presentan baja intensidad laboral, mientras que ocurre lo contrario con las actividades caracterizadas por intensidades laborales medias o altas.

Ahora bien, las tendencias que muestra la evolución reciente del patrón de especialización global no se reproducen de forma homogénea con los distintos socios, sino que se presentan cambios muy marcados que, como ya fue observado, resultan favorables a Brasil.

Si bien las relaciones comerciales con China muestran una mejora impresionante en el DC, pasando de -453 milésimos en 1993 a 168 milésimos en el primer semestre de 2005, esas relaciones pueden asimilarse claramente a las de carácter Norte-Sur: Argentina muestra ventajas en productos primarios y las MOA y desventajas en las MoI. Una característica notable en el comercio argentino con China es la concentración de las ventajas comparadas en unos pocos productos, todos pertenecientes al rubro de las oleaginosas.

En ese contexto la mejora en el DC con China tiene su mayor explicación en el desempeño que presentan los productos primarios y las MOA junto a una reducción en el desempeño comercial negativo de las MOI. Sin embargo, no es ocioso recordar en esta instancia que la elevada especialización comercial que presenta la economía argentina con algunos de sus principales socios puede interpretarse no sólo como un signo de debilidad por la volatilidad resultante de su poco diversificado "portafolio exportador", sino como síntoma de que ciertos fenómenos positivos señalados por la literatura del crecimiento endógeno (learning by doing, externalidades pecuniarias y tecnológicas, entre otros) no han tenido lugar aún con gran intensidad (Agosin, 2006).

En cuanto a la relación comercial con Brasil, la evolución del desempeño comercial con este país en los últimos diez años no puede comprenderse cabalmente sin hacer referencia a las interacciones en esa misma materia que han tenido lugar con eu y la UE, dado que, como argumentamos aquí, la nación vecina ha experimentado un desvío de nuestras importaciones en su favor en evidente detrimento de estos últimos dos socios.

El comercio con EU, por su parte, podría ser asimilado a lo que en la primera parte de este artículo fue presentado como el que tiene lugar con otro país más avanzado tecnológicamente y que, al mismo tiempo, dispone de una dotación de recursos naturales tal que dificulta el desempeño comercial de la nación periférica, aun en los sectores en lo que presenta ventajas comparativas con los otros destinos. La teoría predice, en estos casos, la existencia de un déficit bilateral muy significativo para el país periférico. 
Esto se vio confirmado durante la década pasada, ya que, dentro de los principales mercados de Argentina, el de eu es el que mostró la contribución más negativa al saldo comercial. Fue la resultante de un marcado desempeño negativo en las MoI, junto a un indicador casi nulo para los productos primarios y levemente positivo para las MOA (los productos energéticos son lo únicos que exhiben un DC mayor del que presenta la economía con el resto del mundo). Sin embargo, debe notarse que esta situación se fue modificando a partir de 1998, cuando empieza a observarse una mejora en el DC con Eu. Primero por la recesión que afectó entonces a Argentina y que redujo sus importaciones de maquinaria industrial. Luego, a partir de una reducción en el nivel de desventajas que presentaban las MOI, particularmente en el sector de maquinarias y aparatos, y de una recuperación comercial en el sector de energéticos.

La relación comercial con la UE se asimila, por otro lado, al que tiene lugar con una región tecnológicamente más avanzada que no dispone de una dotación de recursos naturales que sea competitiva con el país periférico. Como fue señalado más arriba, cabría esperar que el patrón de especialización de este último se oriente hacia los recursos naturales. Esto es lo que sucede en la relación comercial de Argentina con la UE, siendo la que mejor reproduce un patrón de especialización primarizado: fuertes ventajas comparativas en productos primarios y sobre todo en MOA (es la región con la que sostiene el mejor desempeño) al tiempo que registra fuertes desventajas en MOI. Pero también con la UE se registra una reducción de las desventajas comparativas durante el último periodo recesivo transitado por la economía argentina, proceso que continúa durante los últimos años a partir de una continuidad de las ventajas presentadas por los productos primarios, una consolidación de las MOA y una reducción de las desventajas de las MOI (en material de transporte y maquinarias y aparatos).

Tal como mencionamos previamente, las tendencias de los últimos años observadas en las relaciones comerciales con eu y la uE encuentran un paralelismo con el desarrollo del patrón de comercio con Brasil. Debe notarse que la relación comercial con este país podría ser asimilada a la que tiene lugar con una nación que detenta un grado de desarrollo tecnológico similar. Una de las hipótesis planteadas en el primer apartado de este análisis es que, por medio de un proceso de integración y en la medida en que exista una relativa armonización de políticas que elimine las diferencias regulatorias, se podría dar lugar a una especialización de carácter intra-industrial. Lo que pudo observarse en la relación comercial con Brasil durante los años que siguieron al nacimiento del proceso de integración fue un DC de las MOA muy inferior respecto del patrón global junto a una mejor performance relativa 
de las mor y desempeños favorables en primarios y energéticos. Sin embargo, durante los últimos años se produjo un creciente y significativo deterioro en el balance comercial con Brasil como resultante de una marcada reducción en el DC positivo que presentaban los productos primarios, MOA y energéticos, y una agudización en el DC negativo de las MOI, particularmente en maquinarias y vehículos de transporte.

Es evidente que las ventajas potencialmente alcanzables del proceso de integración regional (aprovechamiento de ventajas comparadas genuinas, mercado ampliado, procesos de aprendizaje, etcétera) parecen encontrarse seriamente en cuestión desde la perspectiva argentina. Entre otros aspectos, se reflejan aquí las diferencias de políticas seguidas por ambos países. Cabe destacar, por ejemplo, el sector de los bienes de capital que para Brasil nunca dejó de ser considerado como estratégico. O el de la producción de terminales móviles al que hicimos referencia anteriormente.

¿Qué conclusiones se pueden extraer de la observación conjunta de los distintos desempeños bilaterales? ¿Qué rasgos particulares presenta la interacción de la relación comercial con los distintos socios en los últimos años? El fuerte deterioro en el DC con Brasil (con un saldo negativo en el balance comercial) coincide con una mejora en el DC con el resto de los principales socios comerciales considerados: no sólo China, sino también eu y Europa.

En este proceso parecen coexistir desvíos de ciertas exportaciones primarias argentinas (trigo, combustibles) y de MOA (lácteos) desde Brasil hacia los otros destinos considerados. Simultáneamente, se estaría produciendo un desvió favorable a Brasil de ciertas importaciones argentinas de mOI que previamente provenían de otros orígenes (EU y UE). Esto significa que elementos que aparecían como permanentes en la relación entre los dos principales socios del MERCOSUR, como la existencia de ventajas comparadas para Argentina en bienes primarios a cambio de una posición superavitaria de Brasil en manufacturas industriales, pueden estar transformándose en una situación de superávit estructural de Brasil a partir de desvíos comerciales desde terceros países favorables a este último.

En este proceso juegan factores tanto de orden macroeconómico (niveles de actividad y tipos de cambio) como microeconómico (crecimientos diferenciales de la productividad) e institucional (falta de armonización de políticas de incentivos) que se vuelve fundamental analizar los efectos de definir el futuro de las relaciones comerciales de Argentina, tanto en el orden regional como global.

En el ámbito regional podría derivarse de este trabajo la necesidad de generar una modificación importante en el patrón de las relaciones comerciales con Brasil. Más allá de la evolución del tipo de cambio bilateral, esto requeriría un fortaleci- 
miento de ciertas políticas microeconómicas por parte de Argentina ${ }^{12}$ y una armonización de las mismas en el nivel regional, a efecto de promover un desarrollo del comercio de tipo intraindustrial y de ventajas comparativas dinámicas regionales en relación con terceros mercados, aprovechando las ventajas derivadas del mercado ampliado y de la colaboración en el nivel tecnológico.

\section{Bibliografía}

Agosin, M. R., Trade and Growth: Why Asia Grows Faster Than Latin America, en Ricardo Ffrench-Davis (ed.), Growth with Equity in Latin America, a ser publicado por Palgrave, London, 2007.

Amadeo, Vieira Ferreira Levy, Beira, Melo Filho, de Miranda, Sigelmann, da Silva Filho y Vescovi, Orçamento de Renunciais Fiscais e Subsidios da Uniao, Brasilia, Secretaría de Política Económica, 2003.

Amsden, A., "The Direction of Trade-Past and Present-and the 'Learning Effects' of Export to Different Directions", Journal of Development Economics, Elsevier, vol. 23(2), pp. 249-274, octubre 1986.

Bekerman, M. y P. Sirlin, "Política Comercial e Inserción Internacional de la Argentina en los años noventa", Boletín del Centro de Economía Internacional, en Luis Eugenio Di Marco (ed.), "En la búsqueda del hombre: la economía del orden nuevo", pp. 197-229, Córdoba, Atenea, mayo, 1995.

_- , P. Sirlin y M. L. Streb, Política económica en experiencias exitosas de Asia. Los casos de Corea del Sur, Taiwán, Malasia y Tailandia, Buenos Aires, Centro de Estudios de la Estructura Económica, Documento de Trabajo, núm. 2, 1995a.

, M., P. Sirlin y M. L. Streb, Las nuevas orientaciones de política industrial, tecnológica y de promoción de exportaciones en Argentina y Brasil. Asimetrías y posibilidades de coordinación, Buenos Aires, Centro de Estudios de la Estructura Económica, Documento de Trabajo núm. 1, 1995b.

-, M. y P. Sirlin, Efectos del proceso de apertura y de integración sobre el patrón de especialización de la economía argentina,
Buenos Aires, Centro de Estudios de la Estructura Económica, Documento de Trabajo núm. 4, 1996.

Bezchinsky, G., R. Bisang y F. Eggers, Tabla de categorización tecno-económica de las producciones industriales argentinas, Buenos Aires, CEPAL, 1992.

Carrera, J., "Dilemas en mitad del río: qué hacer con el MerCosur". En Neffa L. y Cordone H. (compiladores) Escenarios de salida de crisis y estrategias alternativas de desarrollo para Argentina, ed. Buenos Aires: CEIL-PIETTE, 2006.

CEPAL, El comercio de manufacturas de América Latina. Evolución y Estructura 1962-1989,LC/ R, núm. 63, Santiago de Chile, CePaL, 1991.

Chudnovsky, D.,A. Lópezy G. Pupato, Las recientes crisis sistémicas en países emergentes: las peculiaridades del caso argentino, en C. Bruno y D. Chudnovsky (comp.), Por qué sucedió? Las causas económicas de la reciente crisis argentina, BuenosAires, Siglo xxI de Argentina Editores, 2003.

De Sousa Melo, P. R., E. C. S. Duarte Ríos y R. M. Vinhais Gutiérrez (2001), Componentes Electrónicos: Perspectivas para o Brasil, Rio de Janeiro, BNDES Setorial, 2001.

Delgado, R., "Asimetrías y competencia: Aportes para un rediseño de los instrumentos comerciales", en B. Kosacoff (Coord.), Evaluación del desempeño y aportes para un rediseño del MERCOSUR: Una perspectiva desde los sectores productivos argentinos", Buenos Aires, CEPAL, 2004.

Devlin, R. y A. Estevadeordal, "What's New in the New Regionalism in the Americas", INTALITD-STA Working Paper, Washington DC, núm. 6, Inter-American Development Bank, 2001.

12 Una propuesta de políticas industriales y comerciales para la Argentina puede verse en Bekerman y Sirlin, 1994). 
Edwards, S. (1998), "Openness, Productivity and Growth: What Do We Really Know?", Economic Journal, 108 (1), Oxford, 1998, pp. 383-98.

Ffrench-Davis, R., "Ventajas comparativas dinámicas: un planteamiento neoestructuralista", Cuadernos de la CEPAL, Santiago de Chile, núm. 63, 1990.

Grossman, G. y E. Helpman, Innovation and Growth in the Global Economy, Cambridge, мIT Press, 1991.

Harrison, A. y G. Hanson, "Who Gains from Trade Reform? Some Remaining Puzzles", NBER Working Paper, 6915, Cambridge, MA, January 1999.

Heymann, D. y F. Navajas, "Coordinación de Políticas Macroeconómicas en MERCOSUR: Algunas Reflexiones", en Ensayos sobre la Inserción Internacional de la Economía Argentina", Documento de Trabajo 81, Oficina de la CEPAL en Buenos Aires, 1998.

Lafay, G. y C. Herzog, "Commerce international: la fin des avantages acquis", CEPII, Económica, París, 1989.

Oliva, R., "Estudo da Competitividade de Cadeias Integradas no Brasil: impactos das zonas de livre comércio. Cadeia: Telequipamentos", Unicamp, Campinas, 2002.
Quenan, C., L. Miotti, G. Gutman y C. Winograd, "Especialización internacional, competitividad y oportunidades comerciales: América Latina y la Unión Europea", mimeo, 1995.

Rama, R., "Productive inertia and technological flows in food and drinks processing", International Journal of Technology Management, vol. 16, núm. 7 , Inderscience Publishers, Olney, Bucks, UK, 1998.

Rodríguez, J., "Renta agraria, monocultivo de soja y consolidación de un nuevo patrón agroalimentario", Buenos Aires, CEA-UBA, Documento de Trabajo, 2004.

Viner, J., The Customs Union Issue, Nueva York, Carnegie Endowment for International Peace, 1950.

Vinhais Gutierrez, R. M. y P. de Almeida Crossetti, "A Indústria de Telequipamentos no Brasil: Evoluçao Recente e Perspectivas", Río de Janeiro, BNDES Setorial, 2003.

Wilkinson, J., "The R\&D priorities of leading food firms and long term innovation in the agrofood system", International Journal of Technology Management, 1998, núm. 16 pp. 711-720. 


\section{Anexo metodológico}

Ya que para definir el patrón de especialización de una economía se deben estudiar simultáneamente las exportaciones y las importaciones, tomamos como variable de análisis al saldo comercial sectorial. Pero los saldos comerciales deben ser normalizados para descontar el efecto de aquellos factores coyunturales que conducen a superávits o déficits comerciales globales.

Es por ello que, para el análisis del patrón de especialización global, trabajamos con el indicador de ventajas comparadas reveladas (VCR), de manera que:

$$
\operatorname{VCR}_{\mathrm{i}}=\left[\left(\mathrm{X}_{\mathrm{i}}-\mathrm{M}_{\mathrm{i}}\right)-\left(\mathrm{X}_{\mathrm{i}}+\mathrm{M}_{\mathrm{i}}\right) *(\mathrm{X}-\mathrm{M}) /(\mathrm{X}+\mathrm{M})\right] * 1000 /(\mathrm{X}+\mathrm{M}),
$$

donde $\left(X_{i}-M_{i}\right)$ es el saldo comercial observado en el sector i, y $\left(X_{i}+M_{i}\right) *(X-M)$ I $(\mathrm{X}+\mathrm{M})$ es un valor teórico que representa el componente sectorial de i en el superávit o déficit global. ${ }^{13}$

Las ventajas comparadas reveladas representan, entonces, balances comerciales sectoriales normalizados, correspondientes a una situación hipotética de equilibrio comercial. ${ }^{14}$ En este sentido, constituyen un indicador de las ventajas comparadas de la nación.

Si bien el indicador de VCR es adecuado para el análisis del patrón de especialización global, este indicador puede generar sesgos importantes para el comercio por destinos comerciales. Estos sesgos serán tanto mayores cuanto más diferentes sean las relaciones entre balance comercial y comercio total correspondientes a cada destinto, por un lado, y al comercio con el mundo, por el otro. En última instancia, el problema está en que el análisis de los intercambios, suponiendo que el comercio equilibrado es mucho más relevante en el caso del comercio con todo el mundo que en el de los comercios bilaterales. En el caso del comercio bilateral pueden no existir fuerzas económicas que generen tendencias hacia un relativo equilibrio comercial, al menos en el corto plazo. ${ }^{15}$

13 Esta definición, ya utilizada por Quenan et al. (1994) difiere de la más tradicional contenida en Lafay y Herzog (1989) que utiliza en el denominador al ingreso nacional. Sin embargo en esta última variante, el indicador no refleja únicamente el patrón de especialización (como en el caso del indicador elegido) sino además el grado de apertura de la economía. Debido a los problemas de medición del ingreso nacional y a los efectos del importante proceso de apertura de la economía, la utilización de esta variante hubiera conducido a importantes sesgos reduciendo la claridad del análisis del patrón de especialización.

14 De ello se deduce que la sumatoria de la VCR de todos los sectores transables es igual a cero.

15 Esto sí podría plantearse para el caso de Brasil, en donde la existencia de un proceso de integración lleva continuamente a negociaciones orientadas a contrarrestar saldos comerciales muy desequilibrados. 
Ante la existencia de estos problemas hemos utilizado para el estudio del comercio con los distintos socios de Argentina un indicador ligeramente diferente al que hemos denominado Desempeño Comercial Normalizado (DCN) o simplemente Desempeño Comercial:

$$
\operatorname{DCN}_{\mathrm{ij}}=\left[\left(\mathrm{X}_{\mathrm{ij}}-\mathrm{M}_{\mathrm{ij}}\right)-\left(\mathrm{X}_{\mathrm{ij}}+\mathrm{M}_{\mathrm{ij}}\right) *(\mathrm{X}-\mathrm{M}) /(\mathrm{X}+\mathrm{M})\right] * 1000 /(\mathrm{X}+\mathrm{M})_{\mathrm{j}},
$$

donde el subíndice i representa a cada uno de los sectores, el subíndice j a cada socio comercial, y la ausencia de subíndices a las exportaciones e importaciones totales.

La diferencia con el indicador de VCR (que es utilizado para el análisis del patrón de especialización global) es que en la normalización del saldo comercial sectorial (determinación del valor teórico) se sigue utilizando el balance comercial global, mientras que en el resto del indicador aparecen variables correspondientes al comercio bilateral. Es decir, son desempeños comerciales correspondientes a una situación de equilibrio comercial global (y no bilateral). Esto significa que la sumatoria del valor de todos los sectores (a la que llamaremos desempeño comercial general) de este indicador para cada destino ya no será igual a cero. Un signo negativo (positivo) indicará que un determinado país tiene — relativamente a su participación en el comercio total— un déficit comercial mayor (menor) o un superávit comercial menor (mayor) que el resto de los países.

El indicador de desempeño comercial presenta, entonces, diferencias con el de ventajas comparadas reveladas. En efecto, la esencia del concepto de ventajas comparadas es la interrelación entre sectores que hace que las ventajas de unos se correspondan con desventajas de otros. En este caso, en el comercio con un país determinado pueden aparecer desempeños positivos o negativos para todos los sectores.

La base de datos utilizada es la del comercio exterior argentino según la Nomenclatura Común del MERCOSUR (NCM) a seis dígitos de desagregación. Esta base fue convertida a la nomenclatura CUCI Rev. 2. La clasificación de intensidad laboral es una versión modificada de la que se encuentra en Bezchinsky et al. (1992). La clasificación de complejidad tecnológica es una versión modificada de la elaborada por la CePAL (1991). Para un detalle de la clasificación utilizada véase el anexo metodológico de Bekerman y Sirlin (1996). 


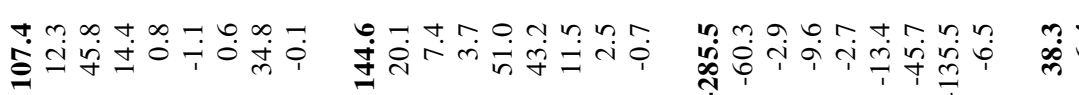

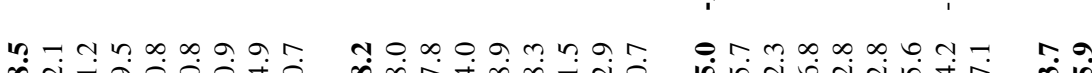

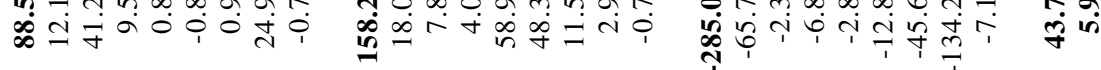

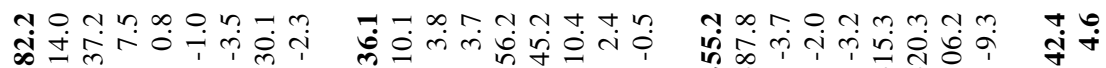

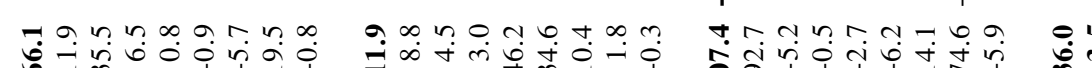
$\stackrel{2}{\check{c}}$

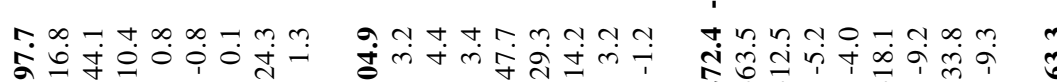

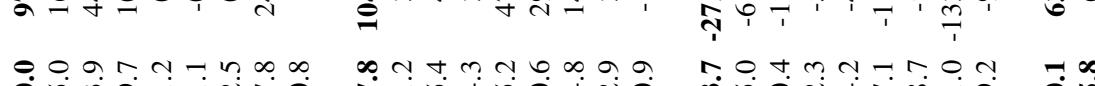

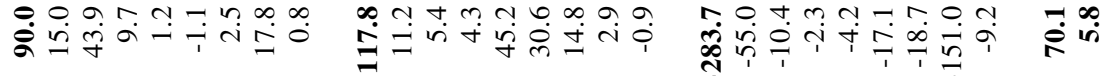

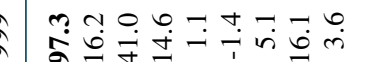

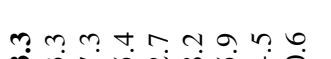

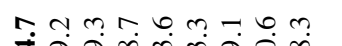

$\stackrel{5}{\ln }$

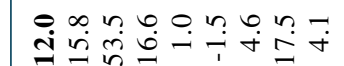

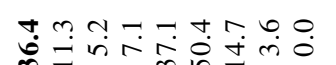

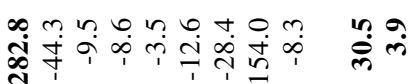

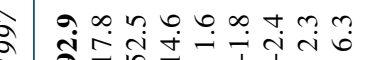

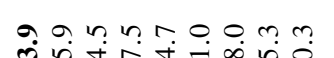

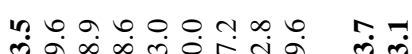

$m+\pi n-\pi) \cdot a n$

ڤ̊ํำ

mำ

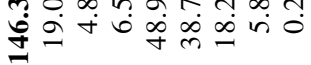

nิ

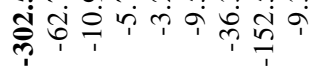

윙ํㅇ

m̊a

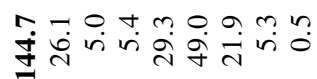

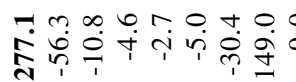

लூฺ

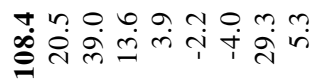

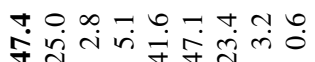

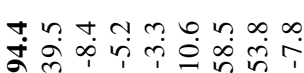

$\stackrel{\infty}{\infty} \stackrel{\infty}{0}$

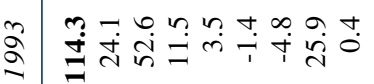

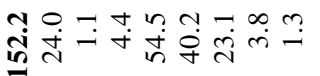

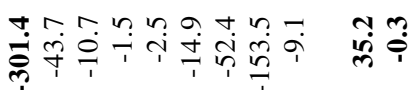



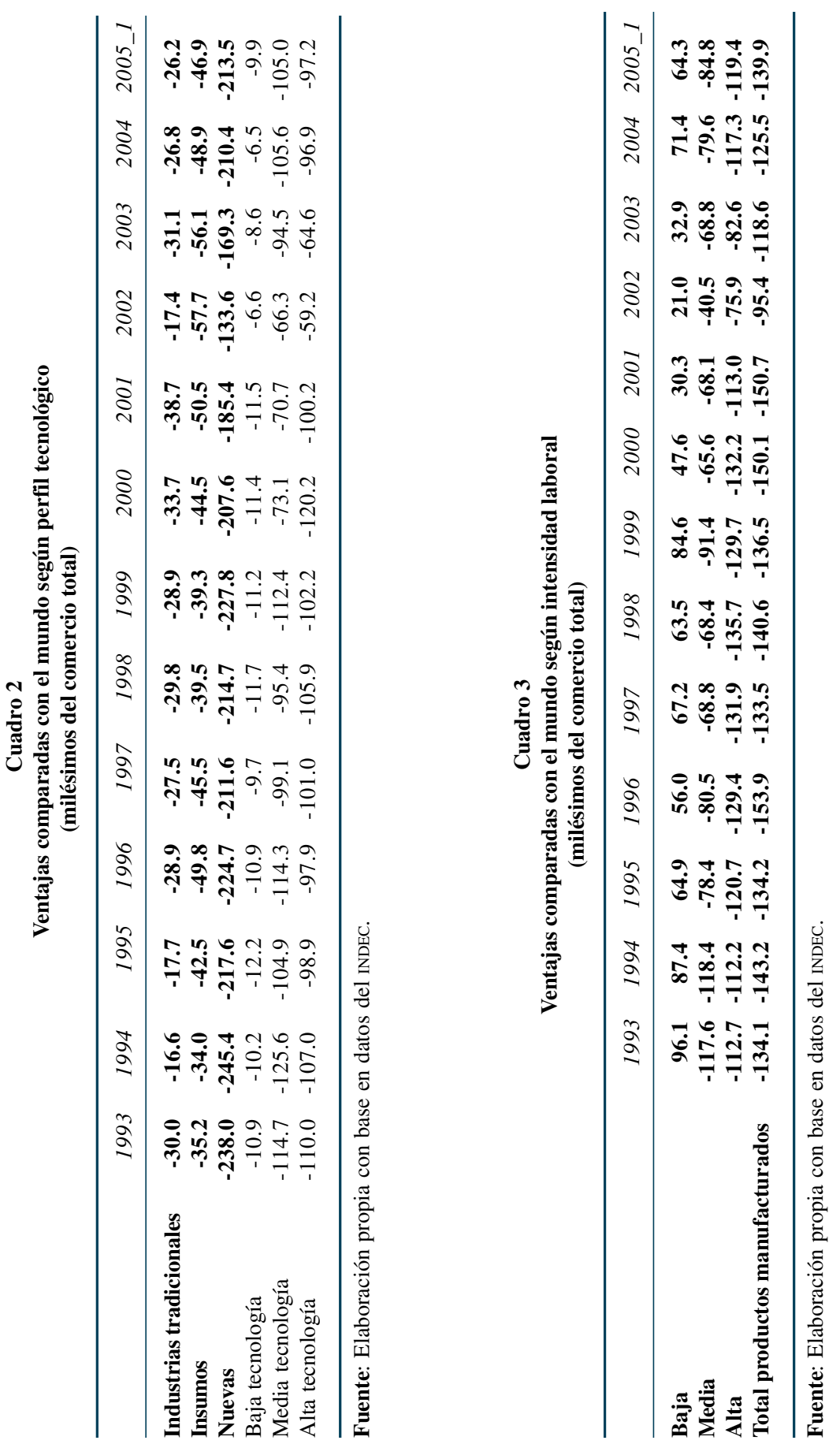


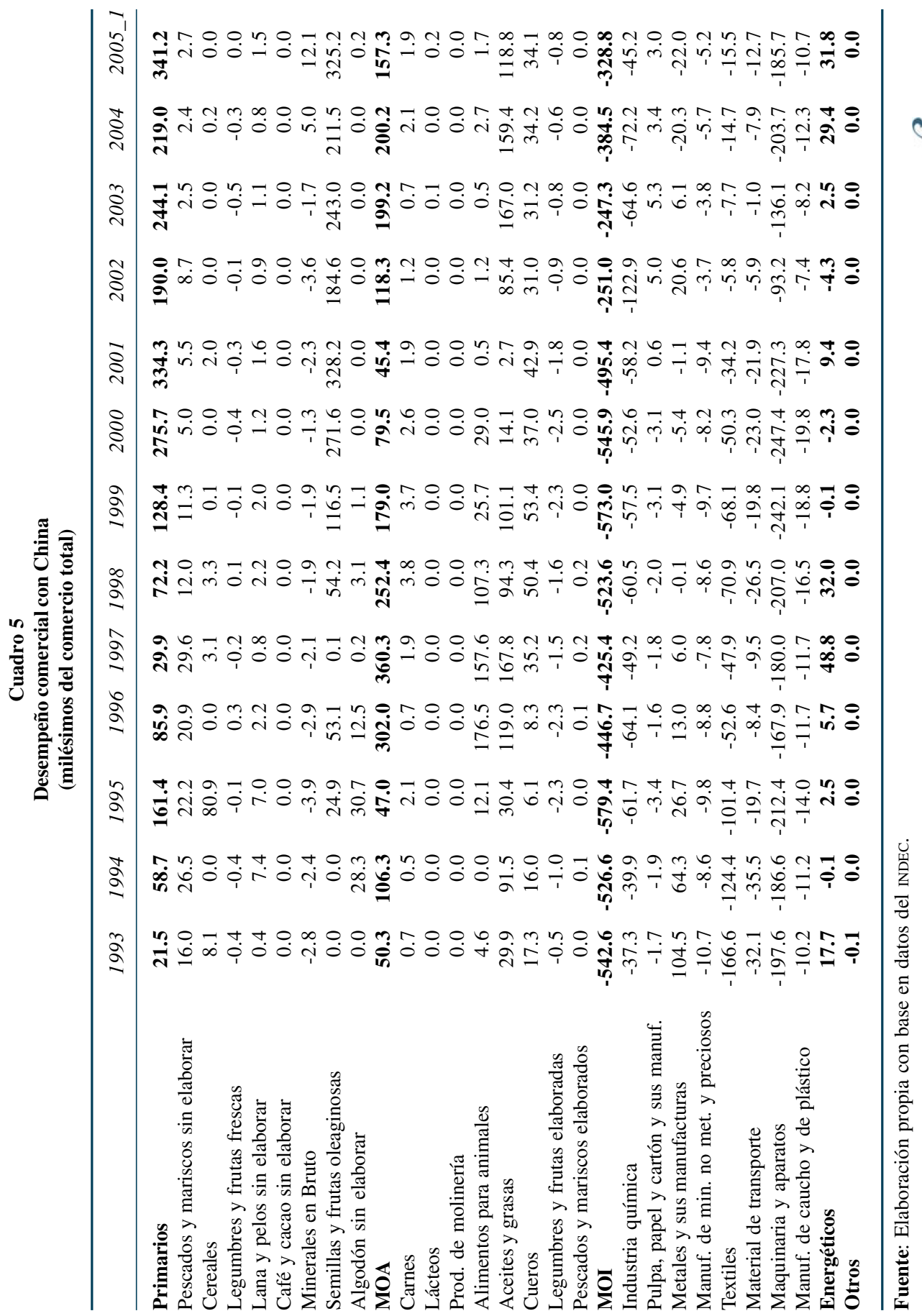

